\title{
Progenitor: el último rol delegado a las máquinas
}

\section{doi: $10.52749 /$ fh.v2i3.7}

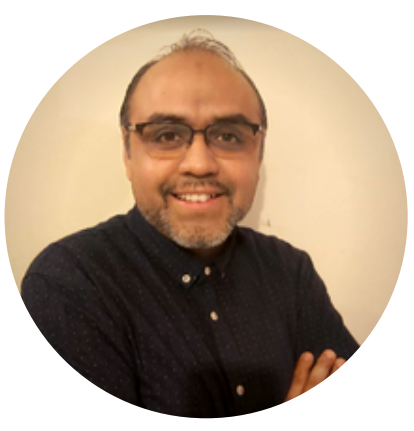

\section{ANGEL CROVETTO}

https://orcid.org/0000-0001-6358-0354

Egresado de la Maestría en Educación con mención en Gestión de Instituciones Educativas por la Universidad Antonio Ruiz de Montoya. Licenciado en Sociología por la Universidad Nacional Federico Villarreal. Especializado en Educación Superior por la Universidad Internacional Laureate. Es profesor en el Centro de Formación en Turismo (Cenfotur), especialista en Ética profesional, Liderazgo y competencias blandas. Expositor para la Cámara Peruana de Comercio Exterior (Camex) y para la Univ. Científica del Sur. Director de proyectos de la Sociedad Secular Humanista del Perú y de la Revista digital Futuro Hoy. Director General del programa digital Transformación Digital de la Educación (TDE).

angelcrovetto1@gmail.com

angelcrovetto.com

Resumen. Con más frecuencia permitimos que las máquinas elijan por nosotros, a través de innumerables algoritmos dejamos que las máquinas conozcan nuestros gustos y deseos y los proyecten ante nosotros para que, en medio de un aura de espejismo de control, elijamos lo que ya está predeterminado, pero, ¿en el fondo estos algoritmos nos conocen? ¿pueden reconocer en qué consiste nuestra humanidad? Este artículo en particular tiene el propósito de explorar la razón del por qué dejamos que las máquinas puedan tomar el control de nosotros, hasta llegar al punto que ellas puedan elegir nuestra existencia y la manera de vivir, como se plantea en la película "I am mother".

Palabras clave: Inteligencia Artificial, Ciudadanía Digital, participación ciudadana

_ ¡Hija! ¿Leíste la lección? Podemos elegir un texto diferente... Es parte de un diálogo de una película de ciencia ficción donde la madre intenta enseñar ética a su joven hija. Exploremos el argumento del film.

La película retrata a un androide que, después de una destrucción total de nuestra especie, se encarga de proteger el último banco de embriones humanos que queda en el planeta con el propósito de encontrar al ser humano mejorado. No solo inteligente, versátil, fuerte, resistente, sino moralmente adecuado para ser el o la persona encargada de repoblar y liderar a las nuevas generaciones de humanos, los que serán diseñados como bebés probeta en una secuencia constante de: crear, educar, evaluar, descartar y otra vez crear hasta encontrar al ser humano ideal según el perfil deseado. Descartando o desechando aquellos que no cumplen los estándares esperados. Este es el argumento de la película "I am mother", del año 2019.

Con más frecuencia permitimos que las máquinas elijan por nosotros. A través de innumerables algoritmos dejamos que las máquinas conozcan nuestros gustos y deseos y los proyecten ante nosotros para que, en medio de un aura de espejismo de control, elijamos lo que ya está predeterminado, pero, ¿en el fondo estos algoritmos nos conocen? ¿pueden reconocer en qué consiste nuestra humanidad? Este artículo en particular tiene el propósito de explorar la razón del porqué dejamos que las máquinas puedan tomar el control de nosotros, hasta llegar al punto en que ellas puedan elegir nuestra existencia y la manera de vivir, como se plantea en la película "I am mother".

En la película se explora el rol del progenitor, circunscrito al cuidado, protección y educación por parte del androide; sin embargo, cabe señalar que el término "progenitor" es solo debido a que es el androide quien selecciona al bebé probeta. ¿Qué significa ser progenitor en este contexto? Consideramos que implica hacerse responsable de una vida vulnerable, dependiente, frágil como la de un recién nacido humano. Visto de esta forma, estamos identificando la expresión empírica de una de las relaciones más profundas de la naturaleza humana, el acto de amar como lo hace una madre o un padre. Expliquemos más este punto.

Podemos afirmar que el acto de amar es propio de los seres humanos conscientes, pero desde la 
ciencia aún es un sentimiento ambiguo para ser estudiado; sin embargo, en los hechos, el amor ha inspirado grandes actos de heroísmo, pasiones y desdichas. Obras de arte que han permitido explorar la grandeza, pero al mismo tiempo las miserias humanas. Las emociones aún siguen siendo un misterio para gran parte de los neurocientíficos. Se puede ubicar ciertas partes del cerebro donde se instalan las emociones más instintivas, donde radica nuestra capacidad de sobrevivir ante situaciones extremas. La amígdala es considerada, por los estudios de la neurociencia, la parte del cerebro que dispara las sensaciones fisiológicas de emociones intensas como: el miedo, la ira, el estrés, etc. lo cual ha permitido al ser humano establecer mecanismos de respuesta rápida que hasta pasan por alto el neocortex del cerebro, la parte más evolucionada y racional del mismo. Lopez Mejía et al. (2009) proponen "cuando se estimula eléctricamente la actividad de la amígdala a través de experimentos, en los humanos se produce miedo y aprehensión (Lanteaume et al., 2007). En los animales, quitar la amígdala genera una conducta de ausencia de miedo" (p.64). Por esta compleja forma en que el cerebro humano procesa las emociones y sentimientos es que las máquinas solo pueden simular las expresiones físicas y observables de las emociones, como el acto de amar.

Asimismo, existen evidencias de que, en el caso de los mamíferos, estos tienden a cuidar a su prole, esto es de forma casi intuitiva; ello instintivamente se hace para preservar la especie. Los progenitores dedican tiempo y esfuerzo a este rol que pretende garantizar el cuidado y la extensión de la vida: "la conducta de los progenitores es un hecho observable (por ejemplo, pasan un tiempo con su descendencia, la alimentan), tiene costos (por ejemplo, gastan energía, tiempo) y tiene efectos sobre su reproducción futura. Todo ello es bastante intuitivo, pero estudiarlo resulta algo más complejo" (Peláez del Hierro et al., 2014, p. 379).

En el caso de los seres humanos el proceso es paradigmático debido a que el cuidado parental se encuentra impregnado por la cultura del grupo humano. Desde esta perspectiva, los seres humanos han establecido diversos mecanismos que garantizan la continuidad de la especie y la transferencia de los genes de una generación a otra; sin embargo, esto varía en la forma en que se realiza. "Pero sí parece que el cuidado de las crías favorece la supervivencia y el éxito reproductivo de éstas lo que, además de ser bastante intuitivo, está demostrado empíricamente" (Peláez del Hierro et al., 2014, p. 382).

Por otro lado, los avances tecnológicos están configurando máquinas que tienen como propósito simular la conducta de los seres humanos, en todo orden de cosas: su inteligencia, su capacidad de toma de decisiones, el cuidado de personas, el lenguaje emocional, etc. Ello implica que existe la tendencia a crear máquinas que se vinculen con nuestra manera de vivir y nos ayuden con las acciones cotidianas que facilitan nuestra existencia. Las máquinas vistas así, son medios para ciertos fines, descartables, y/o modificables por versiones cada vez más amigables, para que sigan cumpliendo con el propósito de servir mejor al ser humano. Al mismo tiempo, estamos trasladando la generación de nuestros recursos económicos, seguridad informática, propiedades, cuidado físico, educación, transporte, a las máquinas autónomas y en la actualidad dichas máquinas nos ayudan a diseñar al tipo de bebé que deseamos según ciertos gustos y preferencias de los progenitores. Creemos que este sería el último rol delegado.

"Ya no se trata de dar un hijo a quien no puede tenerlo, sino, a través del diagnóstico preimplantatorio, dar un hijo de "buena calidad" que satisfaga los deseos de los padres, aunque no existan problemas de esterilidad; estos son los llamados "bebés a la carta" (KUYUMDJIAN de WILLIAMS, P. 2010. p. 122).

Debemos resaltar que la maximización de las capacidades humanas es la aspiración del transhumanismo. Para llegar a ese nivel se exploran diversas tecnologías como el conjunto de tecnologíass NBIC (nanotecnología, biotecnología, informática y ciencias cognitivas). En ellas se va descubriendo la manera de preservar nuestra calidad de vida, mejorando la salud, nuestras capacidades, facilitando nuestra existencia y relación con el entorno, es en este sentido que las máquinas van cobrando más y más vigencia. Nosotros -los humanos- creamos máquinas en la 4ta revolución industrial que facilitan nuestra vida de forma segura y amigable; sin embargo, ello puede entrar en colisión con ciertas perspectivas que consideran que 
nuestro futuro puede estar en conflicto con nuestras aspiraciones, configurándose una paradoja. Explico mejor esto último.

En el artículo "La medida del hombre" Víctor García-Belaunde (2020) explora la posibilidad, aún remota, pero plausible, de que las máquinas lleguen a desarrollar una súper inteligencia hasta el punto de poder tener cierto sentido de autopreservación y existencia de sí mismo. Ello implicaría que estaremos ante la manifestación de una nueva forma de vida basada en silicio y no en carbono. Una forma de vida que requiere cierto grado de consideración de derechos y deberes. En la película que estamos analizando en este artículo, podemos notar que el propósito del androide es preservar la vida de la especie humana, lograr encontrar al mejor de nosotros para liderar el futuro, es decir, la máquina sigue estando al servicio de los humanos aun a costa de la vida de los mismos seres humanos que la crearon. La máquina en este sentido está comprometida con el futuro de la especie y solo ve como parte del proceso el desechar a aquellas personas que no cumplen las expectativas.

Ahora bien, ¿de quién aprendió esta simulada conducta moral? Las máquinas son programables y aprenden de sus progenitores, en este caso de los humanos. Homo Sapiens que hemos aprendido a su vez a descartar o desechar cuando no nos sirve algo, somos una especie que aún vivimos en el paradigma antropocéntrico; una especie que hasta la fecha aún no ha aprendido a vivir con sus virtudes y vicios. "I am mother", es una profunda exploración de nuestro sentido de humanidad. Dotar de derechos a seres creados de silicio sería un paso monumental en nuestra existencia como especie; sin embargo, aún es muy lejana esa posible situación [1]. Pero aquí radica la paradoja, en la actualidad estamos dando más y más poder a las máquinas para que controlen nuestra existencia y futuro, sin darnos cuenta de que cuando las máquinas puedan hacerse de un sentido de conciencia seremos completamente dependientes de ellas y habremos dejado de controlar nuestro futuro.

"I am mother", es una expresión paradigmática de ese futuro que vamos configurando casi de forma inconsciente. Un futuro en el que las máquinas puedan decidir por nosotros, tal como lo hace un corrector de texto; corrigiendo el lenguaje escrito de nuestra existencia. Sin embargo, tal como lo tocamos líneas arriba, hay algo que aún para las máquinas más sofisticadas puede ser un misterio. El amor parental que profesan los progenitores humanos. La película brinda una perspectiva animista de las máquinas producto de la interacción que tenemos con ellas, les asignamos cierta valoración y con ello se produce un cambio en nuestra forma de verlas. El androide en la película provoca una sensación de amor por parte de la niña elegida como líder de la humanidad. Un amor que hasta el momento sólo es experimentado por el ser humano.

\section{A manera de conclusión}

Por último, "I am mother" también pone en cuestionamiento cómo nosotros tratamos de preservar cierto atisbo de emocionalidad al crear máquinas que también puedan simular esos efectos, pero ello implica vivir en un mundo de espejos que se colocan uno frente al otro, perdiéndonos en sus imágenes. En otras palabras, creer que una máquina ama, como la mostrada en la película, es vivir una mentira. ¿Por qué dejamos que las máquinas puedan tomar el control de nuestro futuro? Ensayemos una respuesta. Pienso que aún no hemos logrado saber qué nos hace humanos: ¿nuestra capacidad de amar? ¿El que somos finitos?, ¿Nuestra conciencia? Probablemente sea una combinación de aspectos que, al lograr cierta sinergia, se convierten en más que la suma de sus partes. Lo humano aún es un misterio, de cualquier forma, muchos afirman que desde el posthumanismo podremos ser mejores seres conscientes a pesar de que dejemos de ser humanos por completo. Saber quiénes somos, cómo somos, podría elevar las posibilidades de predecir quiénes aspiramos ser, ello implica tener un propósito como especie y en consecuencia deberíamos tener cierto grado de control sobre nuestro futuro, por lo tanto ¿por qué delegamos a las máquinas el rol de progenitor que asegura nuestro futuro como especie?

Finalmente, lo cierto es que lo biológico de nuestra humanidad se va transmitiendo de generación en generación; sin embargo, en la película estamos apelando al cálculo estadístico, probabilístico de ceros y unos para saber a quién heredar nuestro legado haciendo que las máquinas asuman esa decisión. Pienso que, si esto ocurre en la realidad, será el último rol delegado a la máquina.

Bueno, al final solo es una película... aunque algunos dicen que la ciencia ficción con el tiempo se 
convierte en ciencia. En este caso, ojalá estén equivocados.

[1] En esta reflexión no estamos considerando a la Robot Sophia como sujeto de derechos a pesar que el estado de Arabia Saudita lo haya reconocido así. Tema que podría ser abordado en otro artículo.

\section{Referencias}

Peláez Del Hierro, F., Fidalgo de las Heras, A., Sánchez, S., \& Caperos, J. (2014) Etología del cuidado parental: evolución, conducta y mecanismos.

https://repositorio.uam.es/bitstream/handle/10486/680464/eto logia pelaez 2014. pdf? sequence $=1$ \&isAllowed $=\mathrm{y}$.

García-Belaunde, V. (2020). La medida del hombre. Futuro Hoy. 1(1), 27-28. https://futurohoy.ssh.org.pe/wpcontent/uploads/2020/12/Garcia-Belaunde-Velarde-V.-2020-Lamedida-del-hombre.-Futuro-Hoy.-Vol.1-Nro.1.pdf

Grant Sputore (Director). I am mother [Película]. Adelaide Studios
López Mejía, D., Valdovinos de Yahya, A., Méndez-Díaz, M., \& Mendoza-Fernández, V. (2009). El Sistema Límbico y las Emociones: Empatía en Humanos y Primates. Psicología Iberoamericana, 17(2), 60-69.

https://www.redalyc. org/articulo.oa?id=133912609008

KUYUMDJIAN de WILLIAMS, P. (2010), "Bebés a la carta". Frente a una nueva eugenesia", Vida y Ética, 11(1).

http://bibliotecadigital.uca.edu.ar/repositorio/revistas/bebes-a-lacarta-eugenesia. $\underline{p d f}$

\section{Cómo citar este artículo:}

Crovetto, A. (2021). Progenitor: el último rol delegado a las máquinas. Futuro Hoy, 2(3), 40-43. https://doi.org/10.52749/fh.v2i3.7

Esta obra está bajo licencia internacional

Creative Commons 4.0 Reconocimiento 4.0. 